ARTICLE HISTORY: December: 19, 2021 Accepted: February 11, 2021 Published: February 19, 2021

УДК $677.014-615.468$ ИННОВАЦИОННЫЕ РАЗРАБОТКИ В ОБЛАСТИ ТЕХНОЛОГИИ И ОБОРУДОВАНИЯ ДЛЯ
ПРОИЗВОДСТВА КОМПОЗИЦИОННЫХ ВОЛОКНИСТЫХ МАТЕРИАЛОВ

Хосровян А.Г.1, Хосровян И.Г.2, Хосровян Г.А.3

${ }^{1}$ Кандидат технических наук, доцент,

Ивановский государственный политехнический университет,

Иваново, РФ;

${ }^{2}$ Кандидат технических наук,

Ивановский государственный политехнический университет,

Иваново, РФ;

${ }^{3}$ Доктор технических наук, профессор,

Ивановский государственный политехнический университет,

Иваново, РФ

\title{
INNOVATIVE DEVELOPMENTS IN THE FIELD OF TECHNOLOGY AND EQUIPMENT FOR PRODUCTION OF COMPOSITE FIBER MATERIALS
}

\author{
Khosrovyan A.G. ${ }^{1}$, Khosrovyan I.G. ${ }^{2}$, Khosrovyan G.A. ${ }^{3}$ \\ ${ }^{I} P h D$ in Engineering, Associate professor, \\ Ivanovo State Politechnical University, \\ Ivanovo, Russia; \\ ${ }^{2} \mathrm{PhD}$ in Engineering, \\ Ivanovo State Politechnical University, \\ Ivanovo, Russia; \\ ${ }^{3} \mathrm{PhD}$ in Engineering, Professor, \\ Ivanovo State Politechnical University,
}

Ivanovo, Russia

Аннотация. Рассмотрены вопросы получения композиционных волокнистых материалов на основе разработки технологии, оборудования и способа получения многослойных волокнистых материалов. Отмечены преимущества разработанных технологий, оборудования и способа получения композиционных волокнистых материалов. Приведены варианты получения композиционных волокнистых материалов в зависимости от исходного сырья и области их применения. Приведены результаты теоретических исследований технологических процессов, протекающих на разработанном оборудовании для получения многослойных волокнистых материалов.

Abstract. The issues of obtaining composite fibrous materials based on the development of technology, equipment and a method for obtaining multilayer fibrous materials are considered. The advantages of the developed technologies, equipment and methods for producing composite fibrous materials are noted. Variants of obtaining composite fibrous materials are given, depending on the feedstock and their field of application. The results of theoretical studies of technological processes taking place on the developed equipment for obtaining multilayer fibrous materials are presented.

Ключевые слова: Композиционный, многослойный, волокнистый, материал, рассортировка.

Key words: Composite, multi-layer, fibrous, material, grading.

На сегодняшний день одним из самых перспективных, актуальных и рентабельных в текстильной промышленности является производство композиционных волокнистых материалов.

Для значительного расширения ассортимента композиционных волокнистых материалов необходимо уделять особое внимание разработкам технологий, способов и оборудования для получения их из натуральных, химических волокон и их смесей.

На наш взгляд необходимо разрабатывать такие способы и оборудование, с помощью которых можно изготавливать различные комбинации слоев, однородных по составу и отличающихся по физико-механическим показателям, с различными наполнителями и армированием, благодаря чему композиционные волокнистые материалы приобретают специфические свойства и могут быть использованы в различных отраслях народного хозяйства. 
Также при разработке способов и оборудования для производства композиционных волокнистых материалов следует принимать во внимание рациональность использования сырья, сокращение технологических переходов и снижение трудозатрат, уменьшение времени на изготовление продукции, повышение качества получаемой продукции, улучшение условий труда и сокращение численности обслуживающего персонала, а также, что особенно важно, непрерывность технологического процесса.

Исходя из вышесказанного, нами разработан способ и оборудование для получения многослойных волокнистых материалов [1,2].

Способ получения многослойных волокнистых материалов, заключается в том, что после разрыхления, очистки, смешивания и чесания, волокнистая масса перемещается в камере для рассортировки волокон с использованием внешних воздушных потоков и созданных внутренних воздушных потоков, направленных в зону формирования волокнистых слоев с разделением воздушноволокнистой массы на составляющие. В камере для рассортировки волокон внешние воздушные потоки направляют горизонтально, изменяя траекторию перемещения воздушноволокнистой массы, при этом траектория перемещения верхней составляющей волокнистого материала увеличена по отношению к траектории перемещения нижней составляющей волокнистого материала. Траекторию перемещения получаемых волокнистых слоев выполняют разновеликой, после чего слои волокнистого материала соединяют со слоем ткани для армирования.

Разработанное оборудование для получения многослойных волокнистых материалов состоит из узлов питания в виде бункера с переменной площадью поперечного сечения или питающего конвейера и камеры рассортировки волокон в виде многоугольника в продольном сечении, содержащей зоны обеспыливания и очистки волокнистой массы и зоны формирования волокнистых слоев с одновременной дополнительной очисткой.

Для увеличения интенсивности разрыхления клочков волокон, вплоть до разделения их на отдельные волокна, и улучшения качества очистки волокнистой массы в оборудовании для получения многослойных волокнистых материалов в зоне питания дополнительно устанавливаются рабочие барабаны, обтянутые пильчатой гарнитурой.

Улучшение качества очистки волокнистой массы в зоне питания достигается благодаря тому, что возле каждого рабочего барабана установлен сороотбойный нож с возможностью изменения его положения и вытяжной канал для непрерывного удаления сорных примесей.

Выпускная зона разработанного оборудования состоит из двух транспортеров для верхнего и нижнего волокнистых слоев, между транспортерами расположено устройство для разматывания и транспортировки ткани для армирования.

Толщина волокнистых слоев на транспортерах контролируется самогрузочными и контролирующими валиками, под которыми находится датчик, передающий сигнал для изменения работы узлов и зон оборудования.

Необходимо отметить, что в камере аэродинамической рассортировки волокон, волокна, имеющие малую скорость витания, увлекаются воздушными потоками и формируют верхний волокнистый слой, а волокна, имеющие большую скорость витания, - нижний слой. Таким образом, верхний слой образуется из более длинных и тонких волокон, а нижний слой - из более коротких и толстых, т.е. верхний волокнистый слой по физикомеханическим показателям будет отличаться от нижнего волокнистого слоя. Также физико-механические показатели верхнего волокнистого слоя, а также нижнего волокнистого слоя будут отличаться от физикомеханических показателей волокнистого материала, полученного после преобразователя прочеса на технологической линии при общепринятом способе получения композиционных волокнистых материалов, с учетом, что исходное сырье будет одно и то же.

Для изготовления композиционного волокнистого материала аналогичного композиционному волокнистому материалу, полученному согласно разработанным нами способом и оборудованием, потребовалось бы согласно общепринятой технологии организовать две технологические линии для получения двух волокнистых холстов с различными физико-механическими свойствами (верхний и нижний слой) с последующим их сложением с армирующим материалом и скреплением на иглопробивной машине.

Нами предложена технологическая линия производства композиционных волокнистых материалов с использованием разработанного оборудования для получения многослойных волокнистых материалов, схема которой представлена на рис. 1 .

Преимуществами предложенной нами технологической линии являются:

- упрощение и сокращение технологического процесса за счет исключения операций, протекающих на преобразователе прочеса, а также операций предварительного скрепления на иглопробивной машине, наматывания в рулон, складирование на раме и сложения волокнистых холстов с прокладыванием между них ткани для армирования, и как следствие, уменьшение времени на изготовление продукции;

- повышение качества получаемой продукции за чет дополнительной очистки и обеспыливания;

- улучшение условий труда и сокращение численности обслуживающего персонала за счет сокращения технологических операций; 
- непрерывность технологического процесса, обеспеченная включением в технологическую линию разработанного нами оборудования, на котором происходит параллельное образование двух волокнистых слоев с последующим их соединением на данном оборудовании с тканью для армирования;

- вариативность технологической линии.

\begin{tabular}{|c|c|c|c|c|}
\hline $\begin{array}{l}\text { Разрыхлен } \\
\text { иеочистка } \\
\text {, } \\
\text { смешиван } \\
\text { ие }\end{array}$ & $\begin{array}{l}\text { Чесани } \\
\mathrm{e}\end{array}$ & $\begin{array}{c}\text { Формирование } \\
\text { многослойных } \\
\text { волокнистых } \\
\text { материалов с вложением } \\
\text { армирующего материала }\end{array}$ & $\begin{array}{l}\text { Скреплени } \\
\text { e }\end{array}$ & $\begin{array}{c}\text { Резка и } \\
\text { наматывание }\end{array}$ \\
\hline
\end{tabular}

Рис.1. Схема технологической линии для получения композищионных волокнистых материалов

В зависимости от используемого сырья и установленного в линии технологического оборудования для разрыхления и очистки, можно получить новые виды композиционных волокнистых материалов различного назначения.

Так при использовании в качестве сырья шерстяных и химических волокон можно получить композиционный волокнистый материал, предназначенный для пошива спецодежды (рабочей одежды, рукавиц, вачег) и спецобуви (чуни).

В таблице 1 представлены результаты испытаний образцов полученного нами композиционного волокнистого материала в испытательном центре «Полматекс» ФГУП «Ивановский научно-исследовательский институт пленочных материалов и искусственной кожи технического назначения Федеральной службы безопасности Российской Федерации», а также представлен костюм сварщика и вачеги, изготовленные из композиционного волокнистого материала.

Используя в качестве сырья современные химические волокна, такие как, кевлар, терлон, арселон можно получить композиционные волокнистые материалы для изготовления изделий специального назначения.

Для получения композиционных волокнистых материалов, которые используются для ремонта подземных коммуникаций (трубопроводов), в качестве сырья используются полиэфирные волокна, а в качестве армирующего слоя используется стеклоткань.

Кроме того, на предложенной нами технологической линии с обязательным включением в нее разработанного нами оборудования для получения многослойных волокнистых материалов, можно получить четырехслойный наполнитель для одеял из смеси хлопковых и химических волокон, а также смеси из шерстяных и химических волокон.

Таблица 1

Результаты испытаний

\begin{tabular}{|l|l|l|}
\hline $\begin{array}{l}\text { Условный } \\
\text { номер } \\
\text { образца, вид } \\
\text { образца }\end{array}$ & $\begin{array}{l}\text { Наименование } \\
\text { показателя, единица измерения }\end{array}$ & $\begin{array}{l}\text { Фактическое } \\
\text { значение } \\
\text { показателя }\end{array}$ \\
\hline $\begin{array}{l}\text { Композиционный волокнистый } \\
\text { материал }\end{array}$ & $\begin{array}{l}\text { Постав сырья, \% } \\
\text { Шерсть-49,6 }\end{array}$ \\
\cline { 2 - 3 } & $\begin{array}{l}\text { Поверхностная } \\
\text { плотность, г/м2 }\end{array}$ & 570 \\
\cline { 2 - 3 } & $\begin{array}{l}\text { Разрывная нагрузка, Н } \\
\text { Размер полоски 50×100мм } \\
\text {-основа } \\
\text {-уток }\end{array}$ & $\begin{array}{l}513 \\
457\end{array}$ \\
\hline \multirow{2}{*}{ Костюм сварщика и вачеги } & $\begin{array}{l}\text { Разрывное удлинение, \% } \\
\text {-основа } \\
\text {-уток }\end{array}$ & 27 \\
\hline
\end{tabular}

Особый интерес представляет использование в качестве сырья коротких льняных волокон. После разрыхления, очистки и чесания полуфабрикат проходит через разработанную нами машину для рассортировки и получения многослойных волокнистых материалов. Если нет необходимости получения композиционного волокнистого материала, можно, исключив операцию армирования, верхний волокнистый слой отправить на изготовление смесовой (хлопкольняной) пряжи, а нижний волокнистый слой - на изготовление нетканого материала - межвенцового утеплителя. 
Большую роль для повышения качества композиционных волокнистых материалов, состоящих из нескольких волокнистых слоев, играет подбор конструкции игл для игольной доски иглопробивной машины для иглопробивной машины и их размещение на игольной доске при прочих постоянных условиях (глубине прокалывания и плотности прокалывания).

Результаты наших экспериментальных исследований позволили выполнить оптимизацию подбора игл и размещение их на игольной доске в зависимости от состава сырья, физико-механических показателей волокнистых слоев и ткани для армирования.

При разработке технологий и оборудования для производства композиционных волокнистых материалов мы одновременно разрабатывали математический аппарат для описания технологических процессов, протекающих на разработанном нами оборудовании для получения многослойных волокнистых материалов $[3,4]$.

Разработанные нами математические модели и программы для численного моделирования могут быть использованы как при оптимизации технологических параметров оборудования для получения многослойных волокнистых материалов, так и при проектировании новых совершенных узлов, устройств и машин [5-7].

\section{Работа выполнена при финансовой поддержке гранта РФФИ, проект № 20-43-370010.}

\section{Список литературы}

1. Патент № 2471897 Российская Федерация. Способ получения многослойных волокнистых материалов и устройство для его осуществления/Хосровян Г.А. Хосровян А.Г. Красик Т.Я. Хосровян И.Г. Жегалина Т.В.Опубл. 10.01.2013.

2. Патент 2595992 Российская Федерация. Способ получения многослойных волокнистых материалов и устройство для его осуществления / Г.А. Хосровян, Т.Я. Красик, М.А. Тувин, И.Г. Хосровян.- Опубл. 05.08.2016.

3. Тувин М.А. Хосровян И.Г., Красик Т.Я., Хосровян Г.А., Тувин А.А. Математическое моделирование процесса движения волокнистой смеси в бункерном питателе с переменной площадью поперечного сечения шахты // Изв. вузов. Технология текстильной промышленности. - 2015, № 2, С. 83-87.

4. Красик Т.Я., Хосровян А.Г., Хосровян Г.А. Методика определения линейной плотности настила на выходе из бункерного питателя, оснащенного системой обеспыливания // Изв. вузов. Технология текстильной промышленности. - 2011, №5. С. $79 \ldots 82$.

5. Хосровян И.Г., Красик Т.Я., Хосровян А.Г., Хосровян Г.А. Разработка теории выравнивающей способности устройства для получения многослойных волокнистых материалов// Изв. вузов. Технология текстильной промышленности. - 2013, № 6, С. 79 ...82.

6. Тувин М.А., Хосровян И.Г., Хосровян А.Г., Красик Т.Я., Хосровян Г.А. Математическое моделирование аэродинамической рассортировки волокон в устройстве для получения многослойных нетканых материалов// Изв. вузов. Технология текстильной промышленности. - 2015, № 6, С. $71 \ldots 76$.

7. Хосровян А.Г., Тувин М.А., Красик Т.Я., Хосровян Г.А., Тувин А.А. Математическая модель движения волокна при его съеме ускоряющимся воздушным потоком с гарнитуры вращающегося пильчатого барабана // Изв. вузов. Технология текстильной промышленности. - 2017, №2. С. 185-188.

\section{References}

1. Patent of Russian Federation № 2471897. A method for producing a multilayer fibrous materials and device for its implementation. Khosrovyan G.A., Khosrovyan A.G., Krasik T.Ya., Khosrovyan I.G., Zhegalina T.V. 10.01.2013. (in Russian).

2. Patent of Russian Federation № 2595992. A method for producing a multilayer fibrous materials and device for its implementation. Khosrovyan G.A., Khosrovyan A.G., Krasik T.Ya., Tuvin M.A., Khosrovyan I.G. 05.08.2016. (in Russian).

3. Tuvin M. A., Khosrovyan I. G., Krasik T. Ya., Khosrovyan G. A., Tuvin A. A. Mathematical modeling of the process of moving a fibrous mixture in a hopper feeder with a variable cross-sectional area of the mine//Izv. vuzov. Tehnologiya tekstilnoj promyshlennosti. - 2015, - No. 2. - pp. 83-87. (in Russian).

4. Krasik T.Ya., Khosrovyan A.G., Khosrovyan G.A. Method for determining the linear density of flooring at the exit of a hopper feeder equipped with a dedusting system//Izv. vuzov. Tehnologiya tekstilnoj promyshlennosti. - 2011. No. 5. - pp. 79-82. (in Russian).

5. Khosrovyan I.G., Khosrovyan A.G., Krasik T.Ya., Khosrovyan G.A. Development of the theory of the leveling ability of a device for producing multilayer fibrous materials//Izv. vuzov. Tehnologiya tekstilnoj promyshlennosti. - 2013, - No. 6. - pp. 79-82. (in Russian).

6. Tuvin M.A., Khosrovyan I.G., Krasik T.Ya., Khosrovyan G.A. Mathematical modeling of aerodynamic sorting of fibers in the device for producing multilayer nonwovens // Proceedings of higher education institutions. Textile Industry Technology. (2015), №6, pp. 119-122. (in Russian).

7. Khosrovyan A.G., Tuvin M.A., Krasik T.Ya., Khosrovyan G.A., Tuvin A.A. Mathematical model of the motion of the fiber when it is removed by an accelerating air flow from the headset of a rotating saw drum // Proceedings of higher education institutions. Textile Industry Technology. $\quad$ - 2017. $\quad$ - №2. $\quad$ - pp. 185-188. (in Russian). 